\title{
Planejamento coletivo do trabalho pedagógico da Educação Física - PCTP/EF como sistemática de formação continuada de professores: a experiência de Uberlândia
}

\begin{abstract}
Resumo: O objetivo do presente trabalho é analisar os elementos constitutivos de uma abordagem crítica de planejamento de ensino, seguido da descrição de uma sistemática baseada nessa abordagem, denominada Planejamento Coletivo do Trabalho Pedagógico - PCTP. Em processo de desenvolvimento desde 1993 no contexto cíe uma estratégia de formação continuada de professores/as de Educação Física da Escola Básica da Universidade Federal de Uberlândia e da Rede Pública Municipal de Ensino de Uberlândia - RME/UDI. Nesse contexto o PCTP passou a constituir parte de uma política inter-institucional de desenvolvimento da Educação Física que procura, dentre outros aspectos, valorizar este componente no sistema escolar, além de promover formação ampliada dos/as educadores/as participantes. Palavras-chave: Educação Física, Planejamento, Formação Continuada.
\end{abstract}

Revendo o desenvolvimento histórico do componente curricular da Educação Física Escolar, é possível identificar a presença de várias abordagens de planejamento educacional/ que tem sido "adotadas" pela área com a finalidade de viabilizar o encontro de uma ou várias teorias desenvolvidas no

* Doutor em Educação Currículo pela PUC/SR Assessor da Área de Educação Física da "ESEAJUFU e da RME/UDI Decente da Faculdade de Educação Física da UFU $\mathrm{FAEFI/UFU.}$

$1 \mathrm{Em}$ termos gerais, pode-se afirmar que planejar é um ato político de interação e linguagem/comunicação orientado para a tomada de decisões num determinado espaço social, institucionalizado ou não, destinado à projeção, programação, elaboração de roteiros, planos e/ou estratégias de ação cuja finalidade é atingir determinados objetivos, evitando, ao máximo, qualquer tipo de improvisação.

Movimento, Porto Alegre, v. 10, n. 1, p. 113-131, janeiro/abril de 2004 
contexto das suas tendências pedagógicas (tradicional, humanista, cognitivista, crítica etc), tendo em vista a sua materialização no contexto escolar.

Entretanto, olhando para o cotidiano escolar, é possível constatar a existência de professores/as de EFI que não seguem nem utilizam, "explicitamente", nenhuma das abordagens de ensino e de planejamento existentes, devido a dificuldades que variam, desde a precária formação inicial relacionada com os processos de reflexão e intervenção pedagógica no campo escolar, a ausência de formação continuada nas redes públicas de ensino, até a constatação da existência da Síndrome da Desistência do/a Professor/a (Bournout), tal como contatado por Munoz Palafox (2001).

Não sendo foco particular de interesse, neste momento, analisar as características de abordagens de planejamento de natureza positivista e/ou existencialista de planejamento, assunto que pode ser encontrado com detalhes na literatura vinculada as áreas de Currículo e de Planejamento Educacional (Domingues, 1986; Ferreira, 1988; Vianna, 1986; Hypolito, 1996; Silva, 1998), nossa preocupação está dirigida, objetivamente, ao processo de construção e compreensão dos processos de planejamento de ensino orientados por perspectivas críticas de educação.

Nesse sentido, o objetivo deste trabalho é identificar, em primeira instância, os principais elementos constitutivos de uma abordagem crítica de planejamento de ensino, para, em seguida, descrever uma sistemática de planejamento e ação formativa denominada Planejamento, Coletivo do Trabalho Pedagógico -PCTP, que vem sendo desenvolvida desde 1993 e implementada nas escolas públicas do município de Uberlândia, a partir de um processo de formação continuada iniciado em $1996 \mathrm{com}$ a finalidade de resgatar e valorizar a Educação Física como componente curricular.

\section{Abordagem crítica do planejamento de ensino}

Apesar de encontrar literatura marxista associada ao pensamento pedagógico brasileiro desde os anos 50 , pode ser observado que o desenvolvimento desta abordagem começou a materializar-se objetivamente na década de 70 nos movimentos populares, nos contextos de sua organização e mobilização (planejamento participativo), na produção de conhecimento na

Movimento, Porto Alegre, v. 10, n. 1, p. 113-131, janeiro/abril de 2004 
lógica desses movimentos (Pesquisa Participante e Pesquisa Ação), na área do ensino por meio das idéias de educadores como Paulo Freire (1975a; 1975b; 1979), Libâneo (1983), Gadotti (1983) e Saviani (1991) e, no campo do currículo, nas obras de Domingues (1986) e Saul (1986). ${ }^{2}$

Enquanto processo dialético, esta abordagem de planejamento pretende objetivar, em última instância, o encontro direto do/a aluno/a com o material formativo (a matéria) tendo o/a professor/ a como mediador.

Independentemente das críticas efetuadas no campo da didática aos estudos de autores progressistas como Libâneo e Saviani (FREITAS, 1995), o planejamento é considerado uma manifestação da prática social, inseparável da totalidade do contexto em que esta inserida. Por esse motivo, cumpre a essa dimensão do trabalho docente uma função histórico-política, pois:

? ou serve para reproduzir a estrutura de classes e seu modelo de desenvolvimento, ou serve para negá-lo a favor de um modelo de desenvolvimento voltado para a emancipação humana e, por outro lado;

? passa por processos racionais de síncrese, análise e síntese de uma série de condicionantes sócio-econômicas, ético-políticas e estético-culturais, necessárias para contextualizar a ação pedagógica:

2 Obviamente, as propostas pedagógico-críticas defendidas por cada um desses educadores, apresentam divergências entre si, de acordo com a concepção e prática social dialeticamente assumida. Como exemplo podemos citar uma das críticas feitas a Paulo Freire por Dermeval Saviani, que chegou a afirmar que somente através da obra "Ação cultural para a Liberdade", conseguiu detectar uma abordagem dialética da educação no autor, até então não configurada em suas outras obras; há, sim, referência a dialética, mas é uma dialética idealista, uma dialética de consciências ()...() Com efeito, de modo especial no caso de Paulo Freire, é nítida a inspiração da "concepção humanista" moderna de filosofia da educação, através da corrente personalista (existencialismo cristão) (SAVIANI, 1983:77).

3 Uma análise crítica das implicações que os trabalhos de Saviani e Libâneo trouxeram para o campo da didática e da organização do trabalho pedagógico a partir da leitura e educação, pode ser encontrada em Freitas (1995: 27-52).

Movimento, Porto Alegre, v. 10, n. 1, p. 113-131, janeiro/abril de 2004 
1. dos processos e as resultantes do fenômeno ensinoaprendizagem escolar;

2. dos aspectos relacionados com a diferenciação do trabalho docente face as diferentes culturas (classes sociais) existentes;

3. dos processos de seleção de conteúdos básicos das matérias de ensino;

4. dos processos mentais relacionados à aquisição e apropriação de conhecimentos (teorias de aprendizagem - teorias movigenéticas);

5. da organização da seqüência lógica e específica metodológica estabelecida para a organização do trabalho pedagógico, as matérias de ensino e as relações multi e interdisciplinares existentes entre as diferentes esferas do saber escolar (Freitas, 1995);

6. da flexibilidade metodológica do professor relacionada à tomada de decisões pedagógicas concretas e específicas de cada sala de aula (Saviani, 1983). ${ }^{4}$

A função e a importância do planejamento de ensino no contexto da pedagogia crítica residem na necessidade dialética de concretizar o trabalho pedagógico por meio de uma atividade mediadora entre os indivíduos e o social, entre os/as alunos/as e

\footnotetext{
4 Depois de realizar uma análise crítica daquilo que Saviani identifica como sendo as Pedagogias tradicional (PT) e nova (PN), este autor definiu os passos metodológicos que devem caracterizar um ensino crítico. 0 ponto de partida é a prática social identificada sincreticamente pelos/as alunos/as, considerando que estes/as se encontram em níveis diferentes de compreensão em relação ao/à professor/a. Isto, ao invés da preparação dos/as alunos/as sob a iniciativa do professor (PT) ou da "atividade" que cabe aos/às alunos/as desencadear com sua iniciativa (PN). O segundo passo é a identificação dos principais problemas postos pela prática social, contrariamente à apresentação de novos conhecimentos por parte do/a professor/a (PT) e à apresentação de um problema que interrompe a atividade dos/as alunos/as como um obstáculo (PN). O terceiro passo é apropriar-se dos instrumentos sociais (não no um obstáculo (PN). O terceiro passo e apropriar-se dos instrumentos sociais (não no prática social. O quarto passo trata da efetiva incorporação dos instrumentos culturais, pratica social. O quarto passo trata da efetiva incorporação dos instrumentos culturais,
transformados agora em elementos ativos de transformação social necessários para transformados agora em elementos ativos de transformação social necessários para expressar de forma elaborada uma nova forma de entendimento da prática social analisada. O quinto passo, considerado o ponto de chegada, corresponderia à propria prática social transformada numa síntese ampliada em que, por suposto, deve encontrar-se, de alguma forma, o/a professor/a. Essa elevação dos/as alunos/as ao pedagógica (SAVIANI, 1983:88-81).
para compreender a especificidade da relação
}

Movimento, Porto Alegre, v. 10, n. 1, p. 113-131, janeiro/abril de 2004 
a cultura social historicamente acumulada, cuja função é facilitar, por meio de complexos temáticos de conteúdos, os conceitos, as atividades, os métodos e as estratégias de ensino, a socialização do conhecimento associado à luta pela democratização da escola e da sociedade.

Para tanto, procura-se:

a transmissão de conhecimento histórica e culturalmente relevante para as classes sociais marginalizadas/excluídas da sociedade;

a assimilação/apropriação ativa de conhecimento, habilidades e competências não em si mesmas, mais voltadas para os interesses majoritários da sociedade, para a reflexão e ação futura sobre o modo de produção da vida social;

a reavaliação crítica de conhecimentos (saber sistematizado);

No que diz respeito ao planejamento de ensino na Educação Física Escolar brasileira, esta vem seguindo os rumos da Filosofia Crítica fundamentando-se nas Pedagogias de Paulo Freire, de Dermeval Saviani - Histórico-Crítica (1991), de Libâneo - Crítico Social dos Conteúdos (1983), Gadotti - Pedagogia do Conflito (1983) e, mais recentemente, das idéias marxistas de Freitas (1995) e neomarxistas de Jurgém Habermas (Kunz, 1994). Cada um desses autores apresentando as suas próprias marcas interpretativas do marxismo.

Historicamente, tem sido possível identificar duas fases de desenvolvimento desta vertente crítica da Educação, intimamente ligadas entre si. Primeiro uma fase de prática e aquisição de conhecimento seguida da realização de pesquisa de DENUNCIA. E, mais recentemente, uma fase que procura, sem evitar a crítica, reorganizar teórica $e$ praticamente a base de conhecimentos da área, que tem como objetivo geral, REINVENTAR a Educação Física fora dos traços característicos da Pedagogia dominante: autoritarismo, individualismo, alto rendimento, $e$ vitória a qualquer custo (Munoz Palafox, 1993: 34).

$\mathrm{Na}$ década de 90, foram divulgadas duas abordagens metodológicas que, caracterizadas como "Tendências de Ensino da Educação Física Escolar", foram associadas aos diferentes referenciais teóricos que fundamentam a "Abordagem Crítica" do planejamento de ensino. Uma denominada Crítico-Superadora,

Movimento, Porto Alegre, v. 10, n. 1, p. 113-131, janeiro/abril de 2004 
de cunho filosófico marxista-leninista (Bracht et al. 1992) e outra Crítico-Emancipadora que, além utilizar a obra de Paulo Freire, vem procurando fundamentar-se, também, no paradigma da Ação Comunicativa de Jürgen Habermas (NEPEF/UFSC-SME/ Florianópolis, 1996; Kunz, 1991; 1994). ${ }^{5}$

\section{Principais diretrizes do planejamento coletivo do trabalho pedagógico-PCTP: a experiência de Uberlândia}

Baseados Abordagem Crítica do Planejamento de Ensino anteriormente esboçada, em 1993 iniciamos um trabalho de assessoria pedagógica junto aos/as professores/as de Educação Física da Escola de Educação Básica da Universidade Federal de Uberlândia ESEBA/UFU e da Rede Municipal de Ensino de Uberlândia RME/UDI, Minas Gerais, em busca da elaboração de um projeto político-pedagógico coletivo fundamentado no princípio da formação continuada de educadores.

A experiência desenvolvida nesse contexto de trabalho favoreceu o desenvolvimento de uma sistemática de planejamento coletivo que, apesar das dificuldades advindas do cenário político e do cotidiano escolar, vem possibilitando, além da formação teórica dos/as educadores/as participantes, a construção de uma proposta curricular denominada Diretrizes Básicas de Ensino da Educação Física para a Educação Básica, bem como a busca de sua implementação, tanto na ESEBA/UFU, bem como na RME/UDI.

5 Em relação a estas duas abordagens, concordamos integralmente com o posicionamento do denominado "Grupo de Florianópolis" quando diz que, como se afirmou anteriormente, estas duas concepções de Educação Física se colocam como superadoras e, de certo modo, sucedâneas da proposta de Ensino Aberto às Experiências de Reiner Hildebrandt e Ralf Landing (...) Apesar dos referenciais teóricos diversos entre as duas concepções aqui citadas (e sem desconhecer o debate acadêmico que envolve as diferenças, principalmente de projeto histórico entre ambas), academico que envolve as diferenças, principalmente de projeto histórico entre ambas), entendemos que a Educação Fisica enquanto praxis social, pode conviver ou tem convivido com as suas diferenças. O mais importante para os profissionais de Educação papel da rede municipal (de Florianopolis) é buscar o entendimento mais amplo do papel da escola pública e o seu próprio, enquanto profissionais desta escola, e, instrumentalizar SME/Florianópolis, 1996:24-25).

Movimento, Porto Alegre, v. 10, n. 1, p. 113-131, janeiro/abril de 2004 
Denominada Planejamento Coletivo do Trabalho Pedagógico PCTP a sistemática em desenvolvimento apresenta como princípio fundamental, o estabelecimento de uma relação dialética entre a teoria e a prática, tendo em vista a transformação político-pedagógica do processo de intervenção dos/as professores/as de Educação Física no contexto escolar.

Orientados pela discussão coletiva, foi definido, inicialmente, que o planejamento coletivo seria caracterizado como um ato de construção e reconstrução permanente daquilo que denominamos didaticamente de realidade intencionalizada no pensamento e na escrita, cuja finalidade é fornecer subsídios teóricos e práticos para agir estrategicamente na realidade vivida, tendo em vista a sua transformação (Munoz Palafox, 2001 p.176)

Não sendo nossa pretensão, neste momento, de descrever e avaliar criticamente a experiência de trabalho coletivo junto aos professores/as de Educação Física Escolar do município, a qual pode ser encontrada nas teses de doutorado de Muñoz Palafox (2001), de Terra (2004) bem como na dissertação de mestrado de Amaral (2003), nosso objetivo limita-se, neste trabalho, a enunciar as principais diretrizes, conceitos e procedimentos que vem sendo sistematizados coletivamente no PCTP/EF a partir da reflexão crítica da realidade vivida e do estudo das bases teóricas que fundamentam a prática do planejamento e da ação pedagógica crítica no contexto da Educação Física Escolar.

\section{Diretrizes, conceitos e procedimentos utilizados no PCTP/EF em Uberlândia, MG}

As perspectivas antropológicas contemporâneas dependem de uma luta em dois niveis: primeiro, uma batalha estrutural de mais direta e intensa participação politica no sentido de abrir caminho para todos e não só para alguns e, segundo, uma guerra de guerrilhas voltada para os atos pequenos e cotidianos de reeducação do homem (Morais, 1994, p.94).

Antes de proceder à apresentação das diretrizes do PCTP/EF, precisamos reafirmar, ainda que possa parecer óbvio, que as mesmas devem ser criticamente analisadas com antecedência, caso se pretenda utilizar essa estratégia de trabalho docente numa determinada realidade social. O motivo desse "alerta" é devido ao de que as mesmas não foram pensadas numa perspectiva universalizante de sociedade. A sua construção vem sendo fruto de uma prática social que, independentemente de 
refletir as condições e determinantes do país, apresenta as suas próprias particularidades e peculiaridades geográficas, políticas, sociais, econômicas e culturais.

De acordo com os procedimentos metodológicos adotados no PCTP, as principais diretrizes implementadas para viabilizar uma proposta curricular de Educação Física escolar são:

1. Constituir um espaço interinstitucional de trabalho coletivo, mediante a promoção de parcerias entre os/as professores/as das redes de ensino público e a universidade, objetivando a construção de uma proposta curricular ampliada, respeitandose as diferenças e particularidades de cada rede de ensino.

2. Estabelecer uma estrutura de assessoria e/ou orientação pedagógica externa, especializada em Currículo, capaz de contribuir para a elevação da consciência crítica dos/as professor/as, e lidando com a sua organização coletiva, uma vez que devemos estimular o pensamento ao entrar em jogo com os conflitos entre as diferentes formas de agir e agir interpretando o real, considerando o inevitável "choque" com as tradições cristalizadas, as concepções sub-repticiamente formadas e os inevitáveis e incontroláveis "acordos tácitos" que caracterizam o currículo oculto (Saviani, 1995, p.20).

3. Criar espaços de reflexão permanente entre os/as educadores/as para estudar e avaliar tanto as conjunturas nacional e regional bem como dos problemas da cidade, para não restringir o planejamento coletivo ao estudo dos componentes técnico-práticos, psicológicos e sócio-políticos da Educação. Isto, devido ao fato de que a prática pedagógica é uma totalidade abrangente, que deve integrar esses componentes e outros, como o conhecimento da realidade, a observação, a verificação e a reflexão epistemológica para tratamento do conhecimento da Cultura, incluídas aqui, a Ciência e a Filosofia (Sarup, 1986; Giroux, 1986).

4. Identificar problemas e dificuldades relacionados, direta e indiretamente, à prática pedagógica por meio da aplicação de diagnósticos de área realizados periodicamente.

Movimento, Porto Alegre, v. 10, n. 1, p. 113-131, janeiro/abril de 2004 
1. Criar calendários anuais de eventos para a realização de atividades de formação, contando com a participação de especialistas nas áreas de Educação e Educação Física de outras localidades do país, para refletirem e debaterem sobre o trabalho realizado no PCTP, contribuindo com subsídios teórico-práticos durante $\mathrm{o}$ processo de construção e implementação da proposta curricular da área.

2. Construir uma Proposta Curricular de Ensino, cuja função é reorientar os/as professores/as no que diz respeito às políticas cultural e identitária da área. Em Uberlândia, essa proposta recebeu o nome de Plano Básico de Ensino - PBE, por conter, dentre outros assuntos, um guia referencial sobre a realidade social e o saber escolar que pode ser trabalhado no cotidiano escolar, na perspectiva de ensino adotada. ${ }^{6}$

3. Construir coletivamente Estratégias de Ensino, orientadas para intervir e avaliar criticamente no cotidiano escolar.

No que diz respeito a este procedimento, torna-se importante ressaltar que, durante o trabalho desenvolvido com os/as educadores/as envolvidos/as no processo entre 1996 e 1998 (MUNOZ PALAFOX, 2001) tornou-se consensual a idéia de admitir que, para além dos diversos sentidos/significados atribuídos na teoria à palavra metodologia, esta tem significado, basicamente, o ato de identificar objetivos de ensino (geralmente estabelecidos)/ seguidos da busca de alguma proposta de aula previamente estruturada numa sucessão de operações/atividades para, em seguida, adequá-la e reproduzi-la na sala de aula. Isto, com a finalidade de alcan-

\footnotetext{
6 Estudando a parte da Teoria do Currículo, que trata do conteúdo de ensino, é possível identificar que os temas curriculares apresentam diferentes niveis de generalidade. No identificar que os temas curriculares apresentam diferentes niveis de generalidade. No
sistema educativo abordam-se problemas curriculares gerais ou macrocurriculares, sistema educativo abordam-se problemas curriculares gerais ou macrocurriculares,
como dizem Tannere Tanner(1980, p.162), referentes à estrutura de todo o currículo no como dizem Tannere Tanner(1980, p.162), referentes à estrutura de todo o currículo no
seu conjunto. São os problemas que tradicionalmente foram tratados desde a filosofia seu conjunto. São os problemas que tradicionalmente foram tratados desde a filosofia
da educação, da sociologia e da didática geral. Dentro dessas perspectivas globais se incluem problemas microcurriculares relacionados com cada matéria ou disciplina em particular, que é o que em nosso contexto deu conteúdo a didática especial (SACRISTÁN e GOMES, 1998, p.123).

7 Nesse trabalho, também percebemos que vários/as professores/as apresentam dificuldades práticas para traduzir as suas intenções de ação ou as práticas de ensino vivenciadas na escola, na forma de objetivos escritos.
}

Movimento, Porto Alegre, v. 10, n. 1, p. 113-131, janeiro/abril de 2004 
çar o(s) objetivos(s) pretendido(s) independentemente da abordagem pedagógica que, na perspectiva do/a professor/a encontra-se subjacente a sua prática docente. ${ }^{8}$

Infelizmente, essa atitude habitual de planejar o ensino, reproduzindo objetivos e estruturas predeterminadas de aula, além de continuar muito presente entre muitos/as professores/as, tem anulado, em grande parte, a sua capacidade de criação, uma vez que este potencial é cerceado pela pré-definição dos rumos que apontam tais propostas de aulas, as quais que podem ser encontradas com certa facilidade na literatura especializada.

Percebido esse "viés", a busca de sua superação tem implicado no PCTP/EF a necessidade de estabelecer alguns "acordos conceituais" entre os/as professores/as, como procedimento inicial necessário para a construção, implementação e avaliação coletiva de Estratégias de Ensino:

Método/Metodologia: Caminho a ser seguido num sentido amplo. Relacionado a um determinado pensamento lógico (indutivo/dedutivo) ou a uma corrente epistemológica (positivista, dialética, fenomenológica, etc);

Estilo/Técnica de Ensino: Sucessão de operações/ atividades seqüencialmente estabelecidas para alcançar objetivos educacionais. Pela sua estrutura, um estilo/técnica de ensino apresenta um caráter de aplicação universalizante, uma vez que pode ser utilizado no tratamento de diferentes temas de ensino, dependendo de suas características e finalidades específicas.

Estratégia de Ensino: Planejamento de um processo de ensino (onde, com que, quando e como), orientado para alcançar uma ou várias competências educacionais. Uma Estratégia de Ensino pode conter um ou mais Estilos/Técnicas de Ensino para atingir os objetivos desejados.

8 Um exemplo dessa situação foi identificado em 1994, no momento em que foi utilizado, no contexto do PCTP/Uberlândia, o livro que trata da abordagem crítico-superadora da Educação Física (BRACHT ei ai, 1992). Depois de analisar um determinado objetivo de ensino, a tendência dos/as professores/as era procurar viabilizá-lo, encaminhando-se a um capitulo encontrado no final do livro, que propõe como estruturar uma aula de Educação Física (p.87-91). Depois de analisada criticamente essa proposta, observamos que a mesma apresentava uma semelhança estrutural muito grande com a dinâmica construtivista de ensino orientada para a estimulação do "conhecimento físico" no contexto da Educação Infantil (KAMII e DEVRIES, 1985, p.63-7).

Movimento, Porto Alegre, v. 10, n. 1, p. 113-131, janeiro/abril de 2004 
A sua realização pressupõe:

a) identificação dos materiais didáticos e do número de aulas disponíveis para se implementar a Estratégia de Ensino;

b) identificação/estudo da zona de desenvolvimento potencial e real dos/as alunos/as alvos da estratégia;

c) identificação de princípios pedagógicos relacionados à/ às teoria/s de aprendizagem subjacente/s à Estratégia de Ensino utilizada;

d) elaboração de um Seqüenciador de Aulas (SA) e de uma Unidade de Avanço Programático (UAP) das ações propostas aula por aula, incluindo possibilidades de variantes.

Torna-se importante destacar que o momento de orientação para sistematizar por escrito as ações previstas numa Estratégia de Ensino criada e vivenciada por um/a ou vários/as professores/as, tornou-se, na nossa opinião, uma das atividades mais interessantes do PCTP/EF De acordo com o nível de compreensão que cada professor/a alcança em relação as Diretrizes Básicas de Ensino propostas, vem sendo observadas diferenças nos procedimentos adotados para elaborar e implementar Estratégias de Ensino. Por exemplo, há quem opta por registrar as ações da Estratégia, primeiro, para depois experimentá-las. Outros/as preferem descrever os objetivos, seguido da construção de um esquema básico de atividades. Por esses motivos, foi surgindo a idéia de criação do SA e da UAP.

Entretanto, quando se procede a sistematizar de forma escrita uma determinada Estratégia previamente vivenciada pelo/a professor/a ou não, foi percebida uma curiosa situação. Alguns/ nas dos/as professores/as que optam por escrever as ações da Estratégia encontram, freqüentemente, dificuldades para associar as ações propostas aos objetivos de ensino inicialmente idealizados. Por outro lado, encontramos, também, vários casos entre aqueles/as professores/as que estabeleceram previamente os seus objetivos de ensino, onde foi apresentada dificuldade para traduzir por escrito as ações que executaram em sala de aula por

9 No Seqüenciador de Aula estão contidos os objetivos gerais e específicos da Estratégia
de Ensino, assim como uma descrição resumida das operações que serão realizadas aula por aula.

Movimento, Porto Alegre, v. 10, n. 1, p. 113-131, janeiro/abril de 2004 
não conseguir explicar, com detalhes, as atividades desenvolvidas na Estratégia à luz dos objetivos inicialmente traçados. Por estes motivos, dependendo da "lógica de pensamento" de cada professor/a, a orientação do processo de escrita de uma estratégia de ensino pode começar utilizando-se, tanto um SA quanto uma UAP.

e) Para além do planejamento, durante o processo de implementação de uma Estratégia de Ensino, elaboração e preenchimento de um Registro de Contingências tendo em vista a sua utilização como instrumento avaliativo para a modificação e/ou recriação coletiva da estratégia entre os/as professores/as que a experimentaram em seu próprio campo de vivência docente. Contingência é entendida no PCTP/EF como sendo uma dificuldade que acontece de forma imprevista durante a vivência de uma estratégia de ensino que exige, naquele momento, uma tomada de decisão imediata.

Modelo de registro de contingências

\begin{tabular}{|c|c|c|}
\hline \multicolumn{3}{|c|}{ Série:__ Turma:___ Prof/a: } \\
\hline Dificuldade apresentada & Tomada de decisăo & Resultados \\
\hline
\end{tabular}

f) Preparação e aplicação do instrumental de avaliação e autoavaliação do ensino, por parte dos aluno/as, incluindo considerações/sugestões sobre o processo vivenciado.

Os instrumentos criados, para atender às necessidades da sistematização das Estratégias de Ensino no PCTP/EF, tem como objetivo que os/as professores/as compartilhem suas experiências e reflitam a sua prática, exercitando, dentre outros aspectos, o ato da escrita daquilo que é vivenciado na sua realidade concreta. Por esse motivo, tais materiais receberam o nome de Instrumentos de Mediação Comunicativa (IMC).

Pela função atribuída aos IMC, esses instrumentos vêm sendo criados, testados e reformulados continuamente até conseguir, pela via do acordo coletivo, a definição de formatos capazes de satisfazer as suas finalidades.

Movimento, Porto Alegre, v. 10, n. 1, p. 113-131, janeiro/abril de 2004 
Longe de serem considerados instrumentos burocráticos, geralmente utilizados para demonstrar ao/à supervisor/a pedagógico/a da escola que o/a professor/a realizou o planejamento do ensino, a função dos IMC foi facilitar os processos coletivos de produção/troca de saberes, de reflexão crítica e de comunicação docente para:

a) refletir e avaliar coletivamente as conseqüências das decisões tomadas;

b) analisar como reagem os/as alunos/as;

c) ver se os conteúdos selecionados são factíveis para um certo ciclo de ensino por meio da comparação das experiências;

d) iluminar o processo de tomada de decisões ou a revisão das decisões já tomadas para reformular e/ou atualizar as Estratégias de Ensino experimentadas;

e) obter subsídios da prática pedagógica que, junto à teoria, permitam a construção de novas Estratégias.

Construir, avaliar e reformular coletivamente os Planos Anuais de Educação Físicos (PAEF's) desenvolvidos para implementar o Plano Básico de Ensino da área, o qual deve estar vinculado tanto ao Plano Básico Curricular da Rede de Ensino, bem como ao Plano Anual da Escola, este último, instrumento de implementação do Projeto PolíticoPedagógico de cada recinto escolar. Seus objetivos são:

a) Comunicar os problemas e dificuldades mais importantes, apresentando idéias e/ou propostas para a sua superação, de acordo com a realidade escolar.

b) Apresentar de forma sistematizada os princípios metodológicos de ensino, as teorias de aprendizagem utilizadas e, principalmente, as Estratégias de Ensino desenvolvidas e sistematizadas pelos/as professores/as em seus próprios campos de vivência docente.

Movimento, Porto Alegre, v. 10, n. 1, p. 113-131, janeiro/abril de 2004 
Em resumo, a construção coletiva de Estratégias de Ensino e de Planos Anuais de trabalho vem tornando-se uma dinâmica de planejamento coletivo útil para ajudar a ensaiar e comparar a colocação em prática de um currículo já decidido (Sacristán e Gomes, 1998).

9. Criação, nas unidades escolares, de Coordenações de Área de Educação Física - (CAEF's) para organizar conjuntamente com os/as pedagogos/as, as ações de planejamento coletivo e da prática pedagógica, quando a escola contasse com mais de três professores/as de Educação Física.

Neste ponto, consideramos importante destacar que, apesar de contar com a possibilidade de organizar coordenações de área de acordo com o Estatuto do Magistério da rede pública de ensino municipal de Uberlândia - RME/UDI, somente um número muito reduzido de escolas contava com essa estrutura até o ano de 1998.

Depois de constatar a possibilidade de contar com este tipo de instância, o coletivo de educadores presentes nas reuniões mensais do PCTP/EF decidiu pela formulação de uma política que contempla-se as finalidades da coordenação de área, o perfil do seu/sua coordenador/a, bem como uma proposta de regimento interno.

Para realizar essa tarefa, uma equipe de professores/as trabalhou durante o segundo semestre de 1998, aproveitando parte da experiência adquirida por aqueles/as que já contavam com essa instância nas suas unidades escolares, incluindo aqui a equipe de Educação Física da ESEBA/UFU, que também vinha trabalhando, há vários anos, com essa estrutura de planejamento.

Após aprovar o documento final, a proposta foi incluída no Plano Anual da área em 1999 para que todas as escolas contassem com uma referência útil à criação de suas CAEF's. ${ }^{10}$ Como resultado dessa ação no ano de 1999 aumentou de 4 para 11 o número de unidades escolares com coordenação de área participando ativamente das reuniões mensais do PCTP/EF.

10 Importante mencionar também, que a elaboração desse documento contou com a colaboração permanente de uma inspetora e dois licenciados em Educação Física formados em Direito, que participam das reuniões de assessoria no contexto da RME/UDI.

Movimento, Porto Alegre, v. 10, n. 1, p. 113-131, janeiro/abril de 2004 
Entretanto, no ano de 2001, no contexto de uma nova administração municipal, as coordenações de área de todos os componentes curriculares foram desativadas, sob o argumento de que algumas coordenações não estavam trabalhando adequadamente por ausência de um projeto que regulasse as suas ações, tal como vinha sendo proposto pela área de Educação Física. A Secretaria Municipal de Educação - SME, por meio do seu Setor de Recursos Humanos, argumentou, também, que diante da falta de critérios para escolha dos/as coordenadores/as de áreas nas unidades escolares, alguns diretores tinham convertido esta função em cargos de confiança, lembrando aqui, que cada coordenador recebia uma complementação mensal equivalente a 16 horas/aula mensais.

Diante disso e, sem contar com nenhuma proposta objetiva por parte da SME orientada para o fortalecimento do trabalho coletivo docente no contexto escolar, no ano de 2003 nos defrontarmos com dificuldades concretas para definir horários conjuntos de trabalho entre as unidades escolares que seriam necessárias para garantir a participação dos/as professores/as nas reuniões mensais do PCPT/EF. Como resultado, a presença média mensal de participação dos professores caiu significativamente nesse ano, aspecto que nos levou a retomar, na rede, o debate em torno da necessária valorização dos espaços de formação continuada dos professores.

10. Criação de espaços alternativos de trabalho e estudo para promover a sistematização das reflexões e das estratégias implementadas e avaliadas coletivamente entre os/as professores/as, vislumbrando a perspectiva objetiva de tornaremse pesquisadores/as em ação. Nesse sentido, foi criado o Simpósio de Estratégias de Ensino em Educação/ Educação Física Escolar devido, dentre outros aspectos, ao fato de que, desde 1996, apesar dos problemas encontrados no cotidiano escolar, vem sendo observado um aumento do interesse e envolvimento no campo da produção de conhecimento entre aqueles/as educadores/as que têm decidido orientar seu trabalho docente para a pesquisa educacional (Muhoz Palafox et ai, 1996 e 2001; Camargo et ai, 1999; Amaral, 2003; Terra, 2004).

Na qualidade de atividade estratégica do PCTP, o Simpósio de Estratégias de Ensino em Educação/Educação Física Escolar, foi projetado, para sua realização, em cinco grandes momentos, interligados entre si:

Movimento, Porto Alegre, v. 10, n. 1, p. 113-131, janeiro/abril de 2004 
$\mathrm{O}$ primeiro momento do processo destina-se à orientação dos/as professores/as interessados em sistematizar, durante o ano letivo, as suas Estratégias de Ensino, seguido da transformação em trabalhos escritos para serem avaliados e apresentados no Simpósio, conforme os seguintes eixos temáticos:

a. Introdução à Escola e Educação Física;

b. Jogo, Aprendizagem Sócio-Crítica e Multiculturalismo Crítico;

c. Esporte, Indivíduo e Sociedade (Teoria e Prática);

d. Expressão Corporal, Aprendizagem Sócio-Crítica e Multiculturalismo Crítico;

e. Exercício, Lazer e Qualidade de Vida.

O segundo momento, consta de reuniões mensais com os grupos de professores/as das instituições envolvidas no PCTP, para definir a equipe coordenadora do evento e planejar, programar e divulgar o Simpósio, local e regionalmente.

O terceiro momento corresponde à realização do Simpósio, com 2 ou 3 dias de duração, contando, após a realização das inscrições dos participantes, de uma Solenidade de Abertura, de Oficinas Pedagógicas, de apresentações das Estratégias de Ensino por parte dos/as professores/as envolvidos no $\mathrm{PCTP} / \mathrm{EF}$ ou não, na forma de comunicações orais ou relatos de experiência, assim como de 3 ou 4 conferências magnas.

O quarto momento destina-se à avaliação do Simpósio, a partir das criticas e sugestões levantados pelos/as participantes.

No quinto momento o coletivo de professores/as envolvidos/as no processo, procedem a elaboração de uma Revista Especial de Educação Física, onde são apresentados, dentre outros, os artigos correspondentes às comunicações orais e aos relatos de experiência apresentadas pelos/as professores/as da ESEBA/UFU, da RME/UDI. Fazem também parte da Revista os artigos da comunicações orais apresentados por professores/as de outras instituições não vinculados/as à experiência de Uberlândia.

O sexto e último momento do processo, consiste em atualizar o "sitio" do Núcleo de Estudos em Planejamento do Ensino e da Cultura Corporal - Nepecc/UFU, com as atividades e artigos apresentados durante o simpósio (www.faefi.ufu.br/nepecc). A

Movimento, Porto Alegre, v. 10, n. 1, p. 113-131, janeiro/abril de 2004 
finalidade é divulgar as ações desenvolvidas procurando-se com isto, contribuir com o reconhecimento e a valorização da Educação Física no contexto público escolar do município de Uberlândia e região.

Planificación colectiva del trabajo pedagógico de la educación física - PCTP/EF como sistemática de formación permanente de profesores: la experiencia de Uberlândia

Resumen: El objetivo del presente trabajo es analizar sobre los elementos constitutivos del proceso de planeación de enseñanza orientado por una perspectiva crítica de educación, seguido de la descripción de una sistemática fundamentada en ese proceso, denominada Planeación Colectiva del Trabajo Pedagógico-PCTP en desarrollo desde 1993 en el contexto de un programa de formación continuada de profesores de educación física de la Escuela Básica de la Universidad Federal de Uberlândia y de la red pública municipal de educación de Uberlândia. En ese contexto, el PCTP pasó a constituir parte de una política inter-institucional de desarrollo de la Educación Física Escolar - EFE, que procura, entre otros aspectos, valorar este componente curricular, además de promover laformación ampliada de los/as educadores/as participantes. Palabras-clave: Educación Física, Planificación, Formación Permanente.

Group planning of the phisical education pedagogic work-pwgp/pe as teacher's continued formation work-pwgp/pe as teacher's continued formation
system: Uberlândia's experience Abstract: The objective of the present work is to analyze the constituent elements of a critical boarding of planning of education, followed of the description of a systematics based on this boarding, called pctp. In process of development since 1993 in the context of a strategy of continued formation of professors of physical education of the Basic School of the

Federal University of Uberlândia and the Municipal Public Net of Education of Uberlândia, it started to constitute part of one Inter-institucional politics of development of the physical education that it looks, amongst other aspects, to

value this curricular component, besides promoting the formation extended of the participant educators Keywords: Physical Education, Planning, Continued Formation.

Movimento, Porto Alegre, v. 10, n. 1, p. 113-131, janeiro/abril de 2004 


\section{Referências}

AMARAL, G. ALVES DO. Planejamento de Currículo na Educação Física: possibilidades de um projeto coletivo para as escolas públicas de Uberlândia, Minas Gerais. São Paulo: Dissertação de Mestrado, PUC-SP junho/2003.

BRACHT et. al. Metodologia do ensino de Educação Física. São Paulo: Cortez, 1992.

CAMARGO A.; AMARAL G.; MUÑOZ PALAFOX G. Jogo e agir comunicativo: Construindo uma Estratégia de Ensino na Educação Física Escolar no contexto do PCTP da SME/UDI/MG. In: CONGRESSO BRASILEIRO DE CIÊNCIAS DO ESPORTE, 11., 1999, Goiânia. Anais... Goiânia: Colégio Brasileiro de Ciências do Esporte, 1999. p. 158-164. Caderno 2.

COUTINHO, C. N. Gramsci: textos selecionados. Porto Alegre: L\&M, 1981.

DOMINGUES, J. L. Currículo como atividade intencional. In: Cappelletti, Isabel F; Masetto, Marcos T. (Org.). Ensino Superior: Reflexões e experiência. São Paulo: EDUC PUC/SR 1986. p. 43-72.

FERREIRA, R Planejamento sim e não. São Paulo: Paz e Terra, 1988

FORQUIN, J. C Escola e cultura: as bases sociais e epistemológicas do conhecimento escolar. Porto Alegre: Artes Médicas, 1993.

FREIRE, R Pedagogia do Oprimido. Rio de Janeiro: Paz e Terra, 1975a.

FREIRE, R Acción cultural para la libertad. Buenos Aires: Tierra Nueva, 1975b.

FREIRE, R Educação e Mudança. 2. ed. Rio de Janeiro: Paz e Terra, 1979.

FREITAS, L. C. de. Crítica da organização do trabalho pedagógico e da didática. Campinas: Papirus, 1995

GADOTTI, M. Concepção Dialética da Educação. São Paulo, Cortez, 1983.

GADOTTI, M. Pedagogia da Práxis. São Paulo: Cortez, 1998.

GIROUX, H. A. Pedagogia Crítica e Intelectual Transformativo. In: FELDENS, M. G. \& FRANCO, M. (Org.). Ensino e Realidade: Análise e Reflexão. Porto Alegre: Ed. Da Universidade, 1986a.

GIROUX, H. Teoria crítica e resistência em Educação. Petrópolis: Vozes, 1986b.

HYPOLITO, D. Formação Continuada: dos desafios às possibilidades no cotidiano escolar. 1996. Dissertação - Pontifícia Universidade Católica, São Paulo.

KAMII, C. ; DEVRIES, R. O conhecimento físico na educação pré-escolar: implicações da teoria de Piaget. Porto Alegre: Artes Médicas, 1985.

KUNZ, E. Educação Física: ensino e mudanças. ljuí: UNIJUÍ, 1991.

KUNZ, E. Transformação Didático-Pedagógica do Esporte. ljui: Unijui, 1994.

LIBÂNEO, J.C. Democratização da escola pública. A pedagogia crítico-social dos conteúdos. São Paulo: Loyola, 1983.

MORAIS, J. F Ciência e perspectivas antropológicas hoje. In. CARVALHO, M. C. (org.). Construindo o saber. Campinas: Papirus, 1994.

Movimento, Porto Alegre, v. 10, n. 1, p. 113-131, janeiro/abril de 2004 
MUÑOZ PALAFOX, G. H. Intervenção político-pedagógica: a necessidade do planejamento de currículo e da formação continuada para a transformação da prática educativa. Tese de Doutorado - Pontifícia Universidade Católica, São Paulo, 2001.

MUÑOZ PALAFOX, G. H. Intervenção político-pedagógica: a necessidade do planejamento de currículo e da formação continuada para a transformação da prática educativa. Tese de Doutorado - Pontifícia Universidade Católica, São Paulo, 2001.

MUÑOZ PALAFOX, G. O que é Educação Física: uma abordagem curricular. Porto Alegre, Escola Superior de Educação Física. Rev. Movimento, Ano 3, n. 4, 1996/1.

MUÑOZ PALAFOX, G., et al. A competição esportiva da Escola como campo de vivência do exercício da cidadania participativa: Projeto Político-Pedagógico em Construção. Revista Brasileira de Ciências do Esporte, v. 17, n. 3, p. 279-287,1996.

MUÑOZ, PALAFOX, G. As tendências pedagógicas em Educação Física e sua relação com as categorias Idealista e Materialista da História. Rev. Motrivivência, n. 6, p. 30-35,1993.

NEPEF/UFSC-SME-Florianópolis. Diretrizes Curriculares para a educação física no ensino fundamental e na educação infantil da rede municipal de Florianópolis. Florianópolis: SME, 1996.

SACRISTÁN, J.; GOMES, A. I. Compreender e Transformar o Ensino. Porto Alegre: ARTMED, 1998

SARUR M. Marxismo e Educação. Rio de Janeiro: Guanabara, 1986.

SAVIANI, D. Pedagogia Histórico-Crítica: Primeiras aproximações. São Paulo: Cortez, 1991.

SAVIANI, N. Currículo e Matérias Escolares: A Importância de Estudar Sua História. Rev. Idéias: Currículo, conhecimento e Sociedade, São Paulo, 1995.

SAUL, A. M. Avaliação Emancipatória: uma proposta democrática no contexto da avaliação educacional. In: Cappelletti, I. F.; Masetto, M. T. (Org.) Ensino Superior: Reflexões e Experiência. São Paulo: EDUC, 1986. p. 73-119.

SILVA, TT. (Org.) Liberdades Reguladas: a pedagogia construtivista" e outras formas de governo do eu. São Paulo: Vozes, 1998.

TERRA, D. V. La construcción del saber docente de los profesores de Educación Física: los campos de vivencia. Barcelona: Tese de Doctorado, Janeiro/2004.

VIANNA, I. Planejamento Participativo na escola. São Paulo: E.RU., 1986.

Recebido em: 12/02/2004

Aprovado em: 05/03/2004

Gabriel Humberto Muñoz Palafox NEPECC/UFU

R. Benjamim Constant, 1286 Bairro Aparecida

38406-039 Uberlândia/MG. Brasil

gabmpalafox@ufu.br

Movimento, Porto Alegre, v. 10, n. 1, p. 113-131, janeiro/abril de 2004 